\title{
Monitoring Systems Parameters, Sensors and Technologies for Renewable Energies: Biogas Case Study
}

\author{
F.P. Silva ${ }^{1}$, R.B. Otto $^{1}$, A.A. Braggio ${ }^{1}$ and D.S. Kitamura ${ }^{1}$ \\ ${ }^{1}$ Laboratory of Automation and Simulation of Power Systems \\ Itaipu Technological Park (PTI) \\ Av. Tancredo Neves, 6731. Foz do Iguaçu - Paraná (Brazil) \\ Phone/Fax number: +55 45 3576.7420, e-mail: felipe.silva@ pti.org.br
}

\begin{abstract}
The pig farming brought a large generation of waste in confined places as an environmental problem. In the biological treatment of this waste, one of the by-products is the biogas. This source of energy has become a growing alternative for the increasing environmental problem in swine farming. With the generation of electricity from biogas it is possible that projects become feasible when investing in this renewable energy. However, with the usage growth, an effective monitoring is even more necessary in order to better understand the process and increase its efficiency. At this point, this work aimed to list parameters and sensors that can be used to monitor all stages of the processes. As a complement, it gives a general insight in two case studies that can be used as a basis for other similar studies.
\end{abstract}

\section{Key words}

electricity generation, transmitters, protocols

\section{Introduction}

In Brazil, the pig farming activity is rapidly developing, and it is in continuous specialization, becoming very competitive internationally. The waste generated in the process of pig farming is an environmental concern and the manure treatment has been studied to minimize the potential pollution caused by this activity [1].

Anaerobic digestion of the swine manure is one of the solutions for the high organic load originated in the process and it has as outcome an organic fertilizer and the biogas, a high-energy fuel.

The price of fossil fuels and the concern about the environment has been increasing in the last decade, and renewable energies such as biogas have become attractive as governments are also adopting laws that encourage citizens to use this kind of energy [2].

For the efficient use of the biogas as an energy source, it is extremely important to monitor all stages of the processes using sensors, instruments and communication equipment. The monitoring system must be robust, with low maintenance requirements. Online information can also be a great help in supporting decision-making and problem solving for operators [3].

Therefore, this paper has the purpose of identifying the main parameters and type of sensors used for monitoring the biogas production process and presenting some technologies for transmitting, storing and visualizing the great amount of data produced in all stages.

Lastly it is presented with two case studies with sensors, parameters and preliminary results of monitoring systems.

\section{Monitoring Parameters and Sensors}

\section{A. Biomass Temperature}

The temperature affects directly the biological activity. These anaerobic microorganisms are very sensitive to temperature variations, and sometimes a small variation can interrupt the production of methane [4].

Best performances for operation of digesters are obtained in two higher temperature ranges from 30 to $40{ }^{\circ} \mathrm{C}$ for mesophilic or 50 to $60^{\circ} \mathrm{C}$ for thermophilic organisms [5].

Three types of sensors are normally used for measuring temperature: resistance thermometers devices (RTD), thermocouples and thermistors.

\section{B. Biomass Physicochemical Properties}

Many physicochemical parameters are used as processes indicator in anaerobic digestion, although the volatile acids is one most sensitive parameters [6]. The relation volatile acids/total alkalinity is key to the success of a good anaerobic digestion. The monitoring of these two parameters may prevent disturbances and potential failures in the digestion [7].

Other parameters such as the difference in the concentration of volatiles solids between the tributary and the effluent indicates the percentage of stabilized 
organic matter during the process [6]. The evaluation of the physicochemical properties is usually performed by laboratorial analysis.

\section{Biomass Flow}

The biomass flow is directly related to the Hydraulic Retention Time (HRT) of the digester. It is essential to measure the total organic load removal. The HRT may vary depending on the substrate [8]. With an inappropriate time, it can have unintended effects in the biogas production.

The available sensors for flow measurement are diverse (ultrasonic, electromagnetic, venturi tubes). Wastewater treatment are usually measured with ultrasonic sensors, but the scum generated in process may interfere and measures must be taken to avoid these situations [9].

In the literature, there has been used a box coupled to the output of a farm bay. By measuring the value daily produced, it is possible to estimate the production for the whole farm [10].

\section{Biogas Production and Flow}

The efficiency of the process is determined by the amount of the biogas produced, therefore its measurement is crucial for digesters monitoring.

The quantification of biogas in field experiments must be made with reliable flowmeters that calculate compensation for Standard Temperature and Pressure (STP) [11].

For this type of measurement there are technologies using ultrasonic, turbine and thermal transmitters, which have disadvantages and advantages as studied by [12].

\section{E. Biogas Quality}

Biogas is composed of several gases such as carbon dioxide, methane, hydrogen sulphide and other trace gases.

The amount of carbon dioxide lowers the heat of the combustion provided from methane. The hydrogen sulphide even at lower concentrations can cause corrosion of equipment and auxiliary parts, reducing their useful life [13]. Sensors with stainless steel (AISI 316L) wet parts are desirable or even mandatory.

Different sensors are used to measure the biogas components. The methane and carbon dioxide are quantified with infrared sensors, whereas hydrogen sulphide and oxygen are measured with electrochemical sensors [14].

Some flowmeters (Figure 1) have been developed to indirectly estimate methane fraction, although not as accurate as the sensors cited above, it includes multiple functions and it can be worthy from maintenance and costbenefit analysis.

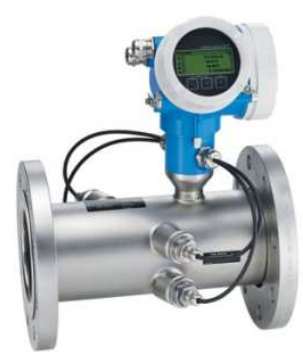

Figure 1. Ultrasonic flowmeter with integrated temperature and methane content measurement

\section{F. Biogas Pressure and Temperature}

Temperature and pressure of biogas are important in the quantification of biogas by non-standard flowmeters, and this parameter can assist in the conversion to STP [15].

The moisture of the biogas is directly related to the temperature. The lower the temperature, the lower the amount of water in the raw biogas [16].

When the biogas is not utilized, it may be burned in open flare, avoiding environmental issues. The temperature of the flame can be directly correlated with the methane concentration in biogas [17].

\section{G. Electrical Energy Production}

The performance of the combined heat and power genset can be estimated by the measurement of the electrical energy produced [18].

The different concentration of the biogas components and parameters has influence on the performance of the genset as studied by [19]. In Gas-Otto (adapted Otto engines for gas) there must be at least $45 \%$ of methane content in biogas in order to operate successfully [20].

\section{H. Power Quality}

A power supply with stable frequency and voltage is desired by the final consumer, but the reality of a power system without disturbances is inevitable [21].

The inclusion of new energy sources in the distribution and transmission systems has grown in many countries, with pros and cons, thus subsidizing the need of monitoring and studying the power quality [22].

In a micro-generator connect to the network grid, [23] encountered high level current harmonics and critical voltage that may be related to the electricity generation.

There are many approaches for measuring both electrical energy production and power quality, starting from power analyzers to ordinary power meters.

\section{Environmental Data}

The knowledge about the environmental data brings an additional information of factors that can interfere in the process of biogas generation which is a biological process. 
In addition, climatic conditions can also explain many events, complementing information from the process's sensors.

\section{Monitoring Technologies}

The technologies used in monitoring systems for biogas production and its energetic use are generally the same as those used in industry. For instance, analogue and digital transmitters are common equipment found in monitoring systems for biogas.

However, other technologies which are used for data communication are disruptive and they will be briefly discussed.

\section{A. Analog Measurements}

Some sensors and transducers used in these systems have an analog voltage or current output signals. The output signal needs to be processed at the acquisition device. As in industrial applications, the analog signals are used to transmit information, and the 4-20mA current loop is the dominant standard (Figure 2).

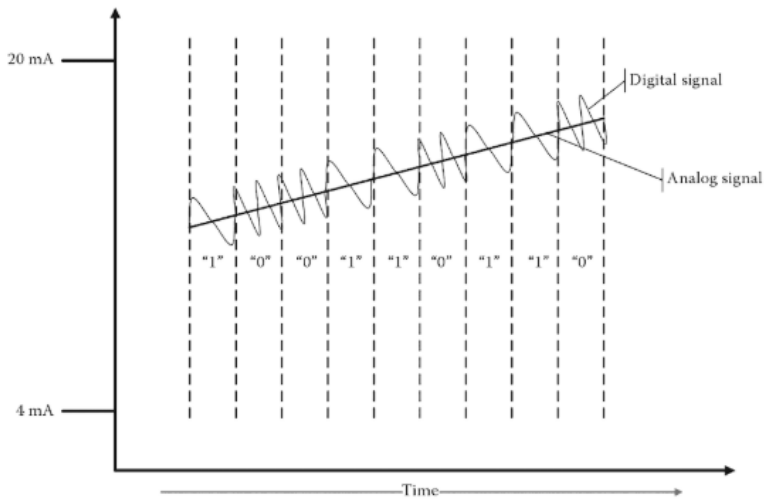

Figure 2. HART signal superimposed over the 4-20 mA [24]

The interface between sensors and monitoring system is performed by an analog-to-digital converter (ADC) connected to a microprocessor. Different from high speed sampling applications, the biogas sensors output can be sampled at a lower rate with a common converter circuit, susceptible of multiplexing.

The measured signal of the biogas pressure and temperature is an example of an analog data.

\section{B. Digital Measurements}

Binary data types, like pulsed signals or dry contact can be used to represent a state. Yet, usually at industrial applications, the voltage range is higher than processor, then the signal needs conditioning.

This high voltage signals on the field-side can be connected to the low-voltage microprocessor using an interface/coupling relay or a controlled current sink.
Also, some sensors have a digital communication interface. The Modbus RS-485 bus is commonly used, but other buses may be found such as Ethernet TCP Modbus.

The HART ${ }^{\mathrm{TM}}$ Protocol, which superimposes a digital signal on top of the 4-20 mA analog signal, is an alternative for simultaneously transmitting additional digital data (Figure 2) using the existing infrastructure [24].

\section{Wired and Wireless Transmission Technologies}

In cases where physical distances are a barrier for data communication, a long-range technology can be used for data communication.

The LoRa® (Long Range) is a physical layer of a wireless modulation used to create communication links over long distances. LoRa ${ }^{\circledR}$ is based on spectrum scattering chirp modulation, which maintains the same low power characteristic as FSK (Frequency Shift Keying) modulations but increases the communication distance [25].

For short distances, wired technologies such as twisted pair cables or fiber optics may be used. Otherwise, measurement devices are nowadays shipped with wireless technologies such as IEEE 802.11 (Wi-Fi), IEEE 802.15 (Bluetooth) and IEEE WirelessHART ${ }^{\mathrm{TM}}$.

\section{Communication Topology}

The communication mechanism is one of the most important pieces of the monitoring systems, as it can dictate how the visualizing and storage application will behave and be developed.

In this subject, streaming message protocols have been developed to adjust the increasing need for scalability and data throughput.

The MQTT (Message Queue Telemetry Transport) is one of these server-client protocols' which runs using a publish/subscribe mechanism. It is a very light binary protocol, being used even in embedded systems (Figure 3) $[26]$.

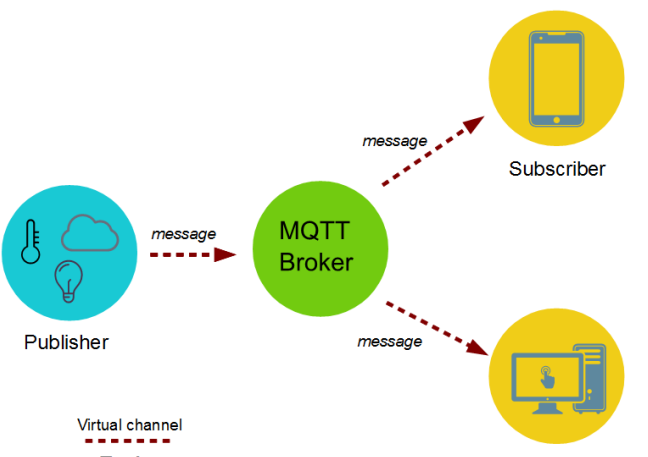

Figure 3. Typical Topology of MQTT Driven Messaging [28]

The AMQP (Advanced Message Queuing Protocol) is another middleware protocol. It is designed to support messaging for almost any distributed application. Both of these protocols use a publish-subscribe technique [27]. 
In order to increase robustness and scalability, Apache Kafka ${ }^{\circledR}$ has become a solution for these problems, often found in communication topologies. The Apache Kafka ${ }^{\circledR}$ may be an aggregator of these technologies such as MQTT and AMQP with advantages of being very scalable, fault tolerant and widely compatible with other messaging protocols.

\section{E. Data Exchange Format}

There are many data exchange formats available on the market, but two of them deserves a special attention due to the wide adoption in the recent developed systems.

The first one is the JSON (JavaScript Object Notation), which is a textual representation defined by a small set of rules according to which the data is structured as shown in Figure 4 [29]:

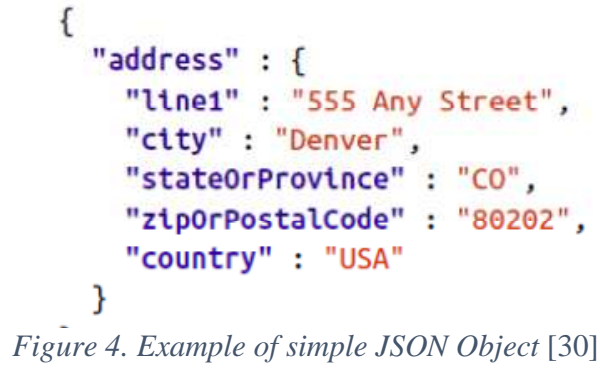

The second is the XML (eXtensible Markup Language), a widely used format across the world wide web. In the design of the XML it was considered some points as: easy readability, no internationalization issues, text orientation and independence of platforms and programming languages.

\section{Case Study: Granja Colombari}

\section{A. Overall Information}

The first Case Study has been conducted in pig farming facility in West of Parana State in Brazil. This farm has about 5 (five) thousand animals and an average production of $36 \mathrm{~m}^{3} /$ day of manure.

The biogas produced from the waste treatment has an average production of $750 \mathrm{~m}^{3} /$ day. For generating electricity, it has a generator set with $100 \mathrm{kVA}$ of installed power, producing an average of $10 \mathrm{MWh}$ of energy [31].

\section{B. Monitored Parameters and Sensors}

In this pig farming unit some parameters were monitored using sensors described in Table 1.

\section{Communication Topology}

The communication topology was based in Ethernet Protocols, such as Modbus TCP and AMQP (Figure 5).

Table 1. Monitored Parameters and Sensors in Colombari

\begin{tabular}{|l|c|}
\hline Parameter & Sensors \\
\hline Biomass Flow & Box Coupled to Farm Bay \\
\hline
\end{tabular}

\begin{tabular}{|l|c|}
\hline Biogas Temperature & Pt100 (RTD) \\
\hline Biogas Flow & Thermal Dispersion Transmitter \\
\hline Biogas Pressure & Capacitive Transmitter \\
\hline Biogas Quality & Methane Infrared Transmitter \\
\hline Electrical Energy & \\
\cline { 1 - 1 } Active and Reactive Power & $\begin{array}{c}\text { Power Meter and Current } \\
\text { Transformers (CT) }\end{array}$ \\
\cline { 1 - 1 } Current and Voltage & Pt100 (RTD) \\
\cline { 1 - 1 } Environment Temperature &
\end{tabular}

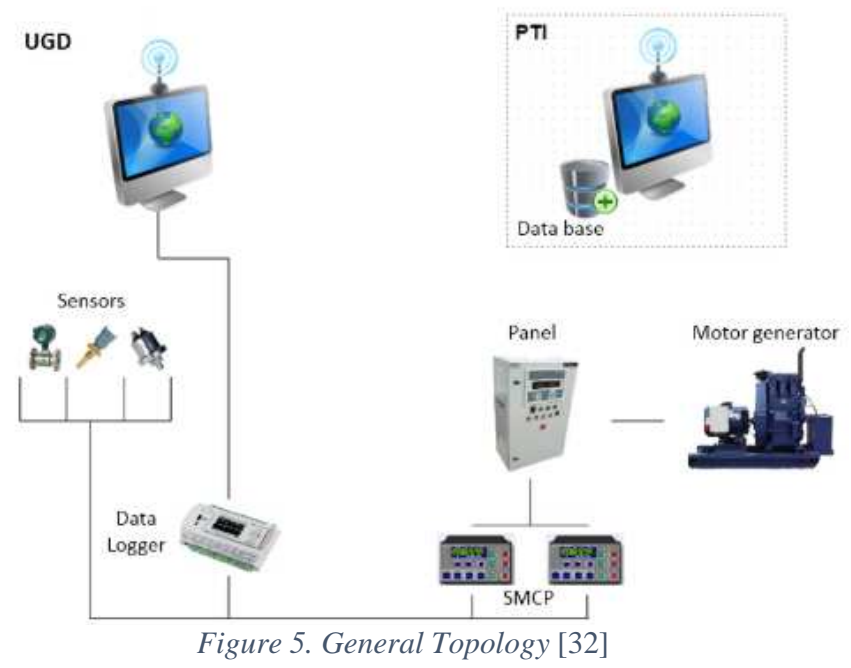

At this topology most of the sensors is using standard 4$20 \mathrm{~mA}$ signals. Although for the power meters with multiple quantities it was necessary a digital transmission with protocol, such as Modbus. A summary of the sensors and transmission technologies is shown in Table 2.

Table 2. Sensors and Transmission Technologies

\begin{tabular}{|c|c|}
\hline Sensors & Signal \\
\hline Pt100 (RTD) & $4-20 \mathrm{~mA}$ \\
\hline Thermal Dispersion Transmitter & $4-20 \mathrm{~mA}$ \\
\hline Capacitive Transmitter & $4-20 \mathrm{~mA}$ \\
\hline Methane Infrared Transmitter & $4-20 \mathrm{~mA}$ \\
\hline Power Meters & RS-485 Modbus RTU \\
\hline Data Logger to Collector & Modbus TCP (Wi-fi) \\
\hline
\end{tabular}

After all the generated data were collected from Data Logger by the Collector Application (UGD), they are sent using AMQP protocol to the database where the gathered data is shown in the supervisory system.

\section{Results}

The use of these instruments and sensors for gathering data were very satisfactory. From the collected data it was possible to raise information about waste generation, biogas production, electrical energy production and even energy efficiency. Some results of this case study were further discussed and analyzed by [31], [32] .

\section{Case Study: Entre Rios do Oeste do Paraná}

\section{A. Overall Information}

The second Case Study is being conducted in Entre Rios do Oeste do Paraná. It is a condominium with 17 
(seventeen) pig farming properties connected through a gas pipeline.

The objective of connecting all these farmers in a gas pipeline is to centralize the use of the biogas in a Thermoelectric Central. The biogas will flow to only one place where electricity will be produced from two generator sets with ca. $600 \mathrm{kVA}$ of installed power.

\section{B. Monitoring Parameter and Sensors (Pig Farm)}

In the pig farm properties, the parameters and sensors (Table 3) were focused mainly in the biogas production and in the stability of the process. So, sensors are going to be installed in the digester and flowmeters will quantify the amount of biogas produced for remunerating the farmers.

Table 3. Monitored Parameters and Sensors in Pig Farms

\begin{tabular}{|l|c|}
\hline \multicolumn{1}{|c|}{ Parameter } & Sensor \\
\hline Biomass Flow & Parshall Flume \\
\hline Biomass Temperature & Pt100 (RTD) \\
\hline Biogas Temperature & Pt100 (RTD) \\
\hline Biogas Flow & Turbine Transmitter \\
\hline Biogas Pressure & Capacitive Transmitter \\
\hline Equipment's state & Interface Relay \\
\hline
\end{tabular}

\section{Monitoring Parameter and Sensors (Central)}

On the other hand, at the Thermoelectric Central the parameters and sensors were focused in the electrical energy production and the efficiency of this process. These parameters and sensors are show in Table 4.

\section{Table 4. Monitored Parameters and Sensors in Central}

\begin{tabular}{|c|c|}
\hline Parameter & Sensor \\
\hline Biogas Temperature & Pt100 (RTD) \\
\hline Biogas Flow and Quality & Ultrasonic Transmitter \\
\hline Biogas Pressure & Capacitive Transmitter \\
\hline \multicolumn{2}{|l|}{ Electrical Energy } \\
\hline \multirow{2}{*}{$\begin{array}{l}\text { Active Power, Reactive } \\
\text { Power, Current, Voltage, } \\
\text { Harmonics }\end{array}$} & Genset Controller 1 and 2 \\
\hline & $\begin{array}{c}\text { Power Meters and Current } \\
\text { Transformer (CT) }\end{array}$ \\
\hline \multicolumn{2}{|l|}{ Environment } \\
\hline $\begin{array}{l}\text { Temperature, humidity, } \\
\text { barometric pressure }\end{array}$ & Weather Station \\
\hline
\end{tabular}

\section{Communication Topology}

For the acquisition of the variables in the pig farms, a data acquisition device was developed (nodes). This device has analog inputs and digital inputs for binary data. It has also support for digital protocol such as Modbus RS-485. In Table 5 it is shown a summary of the sensors and transmission technologies used for this topology.

The generated data in pig farms are sent to the Central (database) through the LoRA Protocol, where a Gateway receives and convert to MQTT using JSON Format. In the Central, the Embedded Controller is responsible for collecting the sensors data and encapsulate to send it to the database, where these data are converted to a user readable Web Interface to supervise the whole system.

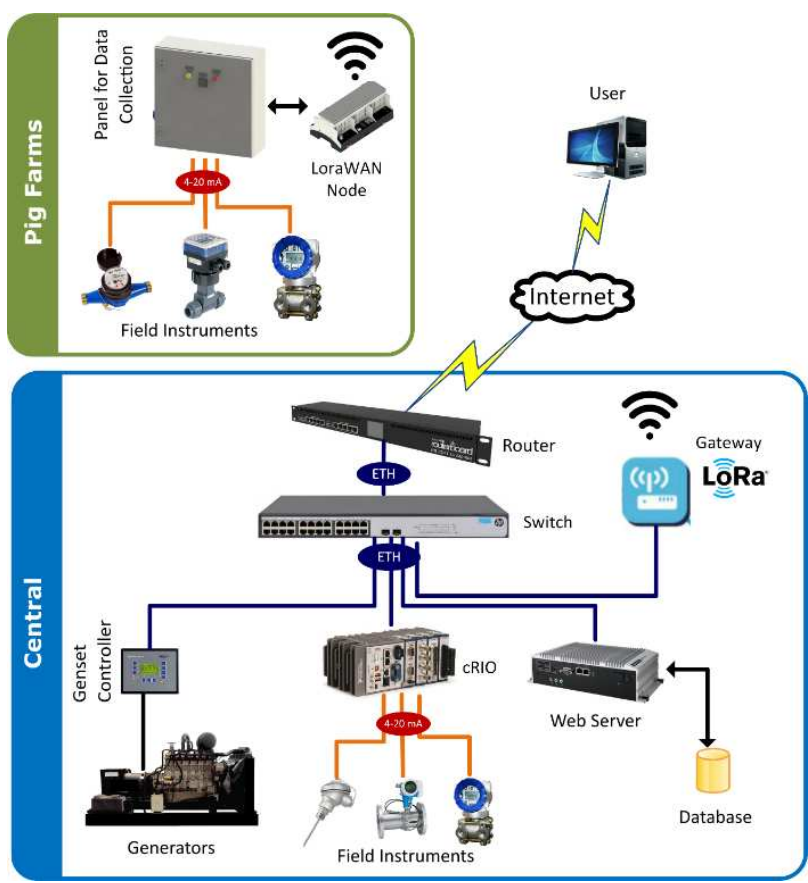

Figure 6. Topology for the Condominium Monitoring System

Table 5. Sensors and Transmission Technologies

\begin{tabular}{|c|c|}
\hline Sensors & Signal/Protocol Sent \\
\hline Pt100 (RTD) & $4-20 \mathrm{~mA}$ \\
\hline Parshall Flume & $4-20 \mathrm{~mA} /$ Modbus RS-485 \\
\hline Turbine Transmitter & $4-20 \mathrm{~mA} /$ Modbus RS-485 \\
\hline Pressure Transmitter & $4-20 \mathrm{~mA}$ \\
\hline Ultrasonic Transmitter & $4-20 \mathrm{~mA} / \mathrm{HART}$ \\
\hline Power Meters & Ethernet (Modbus TCP) \\
\hline Weather Station & Ethernet (Modbus TCP) \\
\hline Embedded Controller & Ethernet (MQTT) \\
\hline Pig Farm Nodes & LoRa ${ }^{\circledR}$ \\
\hline Central Gateway & Ethernet (MQT) \\
\hline
\end{tabular}

\section{E. Results}

This study is being conducted and the data is still being collected. Further papers will discuss the obtained data. As for the monitoring system, the topology is very effective and low maintenance. It was designed to be totally configurable by the user in the Central as the endpoints transmit only raw data which is only converted to shown to the final user. The protocols are widely used and scalable, allowing new pig farms to connect and send new data.

\section{Conclusion}

For transmission the Message Stream Protocols such as MQTT and Kafka ${ }^{\circledR}$ are recommended for scalability. In the field devices, standard transmission technologies such as 4-20 mA analog signal are desirable as they are widely used, and problems are easily diagnosed.

In the long-range transmissions for non-deterministic applications, the radio protocols such as LoRa ${ }^{\circledR}$ can be used, considering low-cost of implementation and scalability. Although for fast transmission rates, fiber optics or 4G Network should be considered. 
As seen in the Case Studies the variety in protocols and transmission technologies are very large. The complexity of the system increases proportionally to its size. Therefore, the advantages and disadvantages may vary depending on the usage. Thus, the protocols and transmission technologies should be carefully chosen always priming scalability and low maintenance.

\section{Acknowledgement}

Acknowledgements for the support and promotion of this work are to Itaipu Technological Park Foundation (FPTI), and Institute of Applied Technology and Innovation (ITAI).

\section{References}

[1] A. Kunz, M. Miele, and R. L. R. Steinmetz, "Advanced swine manure treatment and utilization in Brazil.," Bioresour. Technol., vol. 100, no. 22, pp. 5485-9, Nov. 2009.

[2] H.-T. Pao and H.-C. Fu, "Renewable energy, nonrenewable energy and economic growth in Brazil," Renew. Sustain. Energy Rev., vol. 25, pp. 381-392, Sep. 2013.

[3] K. Boe, D. J. Batstone, J.-P. Steyer, and I. Angelidaki, "State indicators for monitoring the anaerobic digestion process," Water Res., vol. 44, no. 20, pp. 5973-5980, Dec. 2010.

[4] M. H. Gerardi, The Microbiology of Anaerobic Digesters. Hoboken, New Jersey: Joh Wiley \& Sons, Inc, 2003.

[5] C. P. L. Grady, G. T. Daigger, and H. C. Lim, Biological Wastewater Treatment, 2nd ed. Boca Raton, FL: CRC Press, 1999.

[6] R. A. Labatut and C. A. Gooch, "Monitoring of Anaerobic Digestion Process to Optimize Performance and Prevent System Failure," in Got Manure? Enhancing Environmental and Economic Sustainability Conference, 2012

[7] L. Björnsson, M. Murto, T. G. Jantsch, and B. Mattiasson, "Evaluation of new methods for the monitoring of alkalinity, dissolved hydrogen and the microbial community in anaerobic digestion.," Water Res., vol. 35, no. 12, pp. 2833-40, Aug. 2001.

[8] J. Jimenez et al., "Instrumentation and control of anaerobic digestion processes: a review and some research challenges," Rev. Environ. Sci. Biotechnol., vol. 14, no. 4, pp. 615-648, 2015.

[9] P. Harremoës et al., "Wastewater Treatment Plants Under Transient Loading Performance, Modelling and Control," Wat. Sci. Tech, vol. 27, no. 12, pp. 71-115, 1993.

[10] S. D. Gomes, R. Y. Nagae, D. C. Zenatti, A. Fazolo, and B. M. Gomes, "Efeito do manejo da lâmina d'água nas características de efluentes gerados na produção de suínos," in I Simpósio Internacional sobre Gerenciamento de Resíduos Animais, 2009, pp. 31-36.

[11] M. Walker, Y. Zhang, S. Heaven, and C. Banks, "Potential errors in the quantitative evaluation of biogas production in anaerobic digestion processes," Bioresour. Technol., vol. 100, no. 24, pp. 6339-6346, 2009.

[12] B. Drosg, Process monitoring in biogas plants, 1 st ed. IEA Bioenergy, 2013.

[13] E. Ryckebosch, M. Drouillon, and H. Vervaeren, "Techniques for transformation of biogas to biomethane," Biomass and Bioenergy, vol. 35, no. 5, pp.
1633-1645, May 2011.

[14] LFL, Biogashandbuch Bayern. Augsburg: Bayerische Landesanstalt für Landwirtschaft, 2007.

[15] J. Martí-Herrero, T. Flores, R. Alvarez, and D. Perez, "How to report biogas production when monitoring small-scale digesters in field," Biomass and Bioenergy, vol. 84, pp. 31-36, Jan. 2016.

[16] M. Persson, Utvärdering av uppgraderingstekniker för biogas, no. November. Malmö, Sweden: Rapport SGC 142, Svenskt Gastekniskt Center, 2003.

[17] T. Mandal, B. A. Kiran, and N. K. Mandal, "Determination of the quality of biogas by flame temperature measurement," Energy Convers. Manag., vol. 40, no. 11, pp. 1225-1228, 1999.

[18] A. Alagumalai, "Internal combustion engines: Progress and prospects," Renew. Sustain. Energy Rev., vol. 38, pp. 561-571, Oct. 2014.

[19] T.-H. Lee, S.-R. Huang, and C.-H. Chen, "The experimental study on biogas power generation enhanced by using waste heat to preheat inlet gases," Renew. Energy, vol. 50, pp. 342-347, Feb. 2013.

[20] T. Al Seadi et al., Biogas Handbook, 1st ed. Esbjerg, Denmark: University of Southern Denmark Esbjerg, 2008.

[21] IEEE, 1100 - IEEE Recomended Practice for Powering and Grounding Electronic Equipment. Institute of Electrical and Electronics Engineers, 2005.

[22] M. H. J. Bollen, P. Ribeiro, I. Y. H. Gu, and C. A. Duque, "Trends, challenges and opportunities in power quality research," Eur. Trans. Electr. Power, vol. 20, no. 1, pp. 3-18, Jan. 2010.

[23] L. R. A. Ferreira, R. B. Otto, D. S. Kitamura, H. V. Scherer, S. N. M. De Souza, and O. H. Ando Junior, "Power Quality Analysis of a Biogas MicroGeneration Unit; Performance Comparative of Distributed Generation in respect to Brazilian National and International Standards," Renew. Energy Power Qual. J., vol. 1, no. 15, pp. 652-657, Apr. 2017.

[24] R. Zurawski, Industrial Communication Technology Handbook, 2nd ed. Boca Raton: CRC Press, 2015.

[25] LoRa Alliance, "A technical overview of LoRa and LoRaWAN,” p. 20, 2015.

[26] J. Mesnil, Mobile and Web Messaging. Sebastopol: O'Reilly, 2014.

[27] J. E. Luzuriaga, M. Perez, P. Boronat, J. C. Cano, C. Calafate, and P. Manzoni, "A comparative evaluation of AMQP and MQTT protocols over unstable and mobile networks," in 2015 12th Annual IEEE Consumer Communications and Networking Conference (CCNC), 2015, pp. 931-936.

[28] F. Azzola, "MQTT Protocol Tutorial: Step by step guide," 2016. [Online]. Available: https://www.survivingwithandroid.com/2016/10/mqttprotocol-tutorial.html. [Accessed: 01-Aug-2017].

[29] B. Smith, Beggining JSON: Learn the preferred data format of the web. Nova Iorque: Apress, 2015.

[30] T. Marrs, JSON at Work: Pratical Data Integration for the Web. Sebastopol: O'Reilly, 2017.

[31] F. P. Silva, S. N. M. de Souza, D. S. Kitamura, C. E. C. Nogueira, and R. B. Otto, "Energy efficiency of a micro-generation unit of electricity from biogas of swine manure," Renew. Sustain. Energy Rev., vol. 82, pp. 3900-3906, Feb. 2018.

[32] R. B. Otto et al., "Proposal of a Supervisory System for Energy Microgeneration Case Study Granja Colombari,” Renew. Energy Power Qual. J., vol. 1, no. 15, pp. 160-166, 2017. 